\title{
Faktor-Faktor yang Mempengaruhi Willingness to Pay Pengunjung Wisata Teluk Kiluan Menggunakan Contingent Valuation Method (CVM)
}

\author{
Roby Sanjaya $^{1}$ dan Endah Saptutyningsih ${ }^{1}$
}

\begin{abstract}
Abstrak: Penelitian ini bertujuan untuk mengukur willingness to pay pengunjung objek wisata Teluk Kiluan untuk pelestarian lingkungan dan untuk mengetahui faktor-faktor apa saja yang mempengaruhi willingness to pay tersebut. Penelitian ini menggunakan data primer dengan jumlah responden sebanyak 100 orang responden dilakukan yang dilakukan dengan purpossive sampling. Willingness to pay dapat diperkirakan denga menggunakan pendekatan contingent valuation method (CVM). Alat analisis yang digunakan pada penelitian ini menggunakan regresi biner logistic pada SPSS. Berdasarkan analisis, nilai rata-rata willingness to pay per orang untuk retribusi masuk adalah $\mathrm{Rp} 8.000$ yang didapatkan dengan melakukan focus group discussion (FGD) kepada 10 orang responden. Faktorfaktor yang diduga mempengaruhi secara signifikan besarnya nilai willingness to pay untuk responden pengunjung objek wisata Teluk Kiluan adalah variabel Pendidikan literasi pelestarian lingkungan, biaya rekreasi, pendapatan dan frekuensi kunjungan. Sedangkan variabel alternative lokasi berpengaruh negatif dan tidak signifikan terhadap willingness to pay.

Kata kunci: WTP; Literasi Pelestarian Lingkungan; Biaya Rekreasi; Pendapatan; Frekuensi Kunjungan; Alternatif Lokasi; CVM; Teluk Kiluan.
\end{abstract}

SITASI:

Sanjaya, R., \& Saptutyningsih, E. (2019). Faktor-Faktor yang Mempengaruhi Willingness to Pay Pengunjung Wisata Teluk Kiluan Menggunakan Contingent Valuation Method (CVM). Journal of Economics Research and Social Sciences, 3(1), 31-37.

\section{Pendahuluan}

Berkembangnya pariwisata di suatu daerah akan memberikan dampak positif untuk masyarakat dalam bidang ekonomi, kegiatan pariwisata adalah faktor penting dalam proses pengembangan ekonomi karena dapat mendorong perkembangan sektor ekonomi nasional, di antaranya dapat meningkatkan keinginan masyarakat untuk membuka usaha baru yang berkaitan denga jasa wisata, seperti: usaha transportasi, akomodasi (hotel, motel, villa, hostel dan penginapan berkelas lainnya), kemudian dari sisi penerimaan yang lain yang bersumber dari pajak, retribusi parkir dan karcis masuk wisata atau dapat mendatangkan devisa dari para wisatawan mancanegara yang berkunjung. Kemudian dari sudut pandang sosial, kegiatan pariwisata dapat memperluas pasar barang-brang lokal pariwisata, memperluas lapangan pekerjaan baru dari perusahaan hotel atau tempat penginapan lainnya, jasa perjalanan, kantor-kantor pemerintah yang mengurus pariwisata dan penerjemah, indutrsi kerajinan tangan dan cinderamata dan lain lain. 
Faktor-Faktor yang Mempengaruhi Willingness to Pay Pengunjung Wisata Teluk Kiluan ...

Tabel 1 Pengunjung Teluk Kiluan

\begin{tabular}{cc}
\hline Tahun & Pengunjung Domestik \\
\hline 2016 & 20.125 \\
2017 & 25.725 \\
2018 & 26.125 \\
\hline
\end{tabular}

Sumber: Dispar Kabupaten Tanggamus

Table 1 menunjukkan bahwa jumlah pengunjung di Teluk Kiluan pada tahun 2016 adalah sebanyak 20.125 orang, sedangkan pada tahun 2017 jumlah pengunjung yang datang meningkat sebanyak 25.725. Jika diperhatikan, terjadi peningkatan yang sangat signifikan sebesar 5.000 pengunjung di tahun 2017. Tetapi pada tahun 2018 peneliti hanya mendapat data sampai bulan September yaitu sebanyak 26.125 pengunjung dan terjadi peningkatan jumlah pengunjung dibandingkan dengan tahun sebelumnya, dalam hal tersebut tidak menutup kemungkinan bahwa akan ada peningkatan pengunjung nusantara ataupun mancanegara yang berkunjung ke teluk kliuan.

Dewasa ini banyak pengunjung yang kurang mengetahui tentang penting untuk menjaga kelestarian lingkungan dan kesadaran diri untuk menjaga lingkungan. Karena dengan semakin banyak pengunjung yang datang ke destinasi wisata, maka kondisi kebersihan lingkungan dan kelestariannya akan terancam. Oleh karena itu lingkungan harus tetap dijaga agar tidak rusak, karena Teluk Kiluan ini merupakan jalur lintas lumba-lumba dari gugusan cengkalik arah selatan sampai cukuk kementara maka kawasan di sekitar Teluk Kiluan ini harus tetap lestari. Sebab jika tidak, hal ini dapat mempengaruhi habitat lumba-lumba, sehingga tidak ada kawanan lumba-lumba yang melintas lagi. Sedangkan dengan adanya lumba-lumba merupakan daya tarik tersendiri yang terdapat di Teluk Kiluan yang tidak dimiliki oleh objek wisata pasir putih yang lain. Maka dari itu, diperlukan upaya untuk melakukan konservasi sehingga lingkungan di sekitar teluk kiluan tetap terjaga kondisinya dan tidak berpengaruh kepada lumba-lumba yang akan melintas. Namun, dalam upaya pelestarian dan perbaikan fasilitas objek wisata Teluk Kiluan dibutuhkan biaya. Biaya tersebut nantinya akan digunakan untuk memperbaiki sarana sanitasi seperti memperbanyak tempat sampah dan lain-lain. Selain untuk membangun sarana dan prasarana, biaya juga dibutuhkan untuk membayar petugas kebersihan di wisata Teluk Kiluan, biaya ini juga bukan merupakan tanggung jawab pemeritah saja, melainkan tanggung jawab bersama.

Penelitian ini dilakukan untuk mengetahui seberapa besar kemampuan pengunjung untuk membayar dalam upaya untuk melakukan perbaikan kualitas lingkungan Teluk Kiluan di Kabupaten Tanggamus menggunakan metode Contingent Valuation Method (CVM). Contingent Valuation Method (CVM) merupakan salah satu metodologi berdasarkan survei untuk mengestimasi besarnya penilaian masyarakat terhadap barang dan jasa serta kenyamanan. Secara hakiki, tujuan dari Contingent Valuation Method adalah untuk mengetahui kerelaan membayar (Willingness to Pay) dari masyarakat dan keinginan menerima (Willingness to Accept) kerusakan suatu lingkungan (Fauzi, 2004).

Dalam upaya pengembangan Wisata Teluk Kiluan di Kabupaten Tanggamus, dibutuhkan adanya sinergi yang harmonis anatara Pemerintah, Masyarakat dan Lembaga terkait. 
Sanjaya \& Saptutyningsih

Faktor-Faktor yang Mempengaruhi Willingness to Pay Pengunjung Wisata Teluk Kiluan ...

Upaya pengembangan Wisata Teluk Kiluan sangat penting untuk dilakukan agar keasrian dari pantai tersebut tetap terjaga, sehingga penulis mencoba melihat lebih lanjut mengenai potensi objek wisata ini.

\section{Tinjauan Pustaka}

Dalam penelitian Amanda (2009), dengan dengan munggunakan metode Contingen Valuation Method (CVM), total $81 \%$ responden menyatakan bersedia untuk membayar dalam upaya pelestarian lingkungan. Hal yang mempengaruhi kesediaan responden tersebut dinilai berdasarkan usia, tingkat Pendidikan, literasi mengenai lingkungan. Ratarata WTP pengunjung yakni sebesar Rp. 3.588,24. Dalam penelitian serupa, Majid (2008) menyimpulkan bahwa factor yang mempengaruhi tingkat kesediaan pengunjung adalah tingkat pendidikan serta pendapatan. Dari total pengunjung yang dating, $86 \%$ persennya bersedia untuk membayar. Nilai WTP pengunjung yakni rata-rata sebesar Rp. 2.106.

Amalia (2011) menggunakan variabel jenis kelamin, tingkat usia, status perkawinan, jumlah tanggungan, tingkat Pendidikan, jenis pekerjaan, dan tingkat Pendidikan untuk melihat kesediaan pengunjung untuk membayar biaya pelestarian lingkungan. Hasilnya menunjukan bahwa, $70 \%$ masyarakat dan $77 \%$ wisatawan bersedia untuk membayar. Tingkat Pendidikan, lama usaha, dan tingkat literasi mempengaruhi besarnya WTP responden. Tidak jauh berbeda dengan Amalia (2011), Sekar (2010) mencoba menggunakan metode regresi linear dan regresi semi log linear untuk mengukur WTP pengunjung. Hasilnya, Status perkawinan dan jarak berpengaruh negative terhadap frekuensi kunjungan wisatawan. Responden yang memiliki tingkat Pendidikan tinggi dan usia mengengah bersedia untuk membayar lebih guna melestarikan lingkungan.

\section{Metode Penelitian}

Subyek dalam penelitian ini adalah para pengunjung di Wisata Teluk Kiluan Kabupaten Tanggamus. Pada penelitian ini jenis data yang digunakan pada sumber data yang diperoleh yaitu data Primer. Data Primer merupakan data yang diperoleh langsung oleh peneliti dengan menggunakan kuesioner dan wawancara kepada pengunjung objek wisata Teluk Kiluan ditempat objek penelitian. Kuesioner berisikan daftar pertanyaan yang berkaitan dengan willingness to pay pengunjung Teluk Kiluan untuk perbaikan lingkungan yang telah disiapkan oleh peneliti terlebih dahulu.

Dalam penelitian ini metode dalam melakukan pengambilan sampel yaitu menggunakan Purpossive Sampling. Purpossive sampling adalah salah satu teknik pengambilan sampel yang mempertimbangkan beberapa syarat terhadap sumber data yang diambil (Sugiyono, 2011). Peneliti menggunakan metode tersebut karena terdapat alasan seperti adanya keterbatasan waktu, biaya dan tenaga. Terdapat beberapa syarat yang digunakan dalam pengambilan sampel ini adalah seluruh wisatawan yang sudah berusia 


\section{Sanjaya \& Saptutyningsih}

Faktor-Faktor yang Mempengaruhi Willingness to Pay Pengunjung Wisata Teluk Kiluan ...

produktif yaitu 15-64 tahun atau minimal sudah menempuh Pendidikan SMP atau lebih dan pengunjung Teluk Kilua.

Untuk mendapatkan data dan informasi yang sesuai dengan kebutuhan penelitian, maka dilakukan pengumpulan data dan informasi yang dilakukan dengan menggunakan Kuesioner/ Angket. Sejumlah pertanyaan secara tertulis yang akan dijawab oleh responden penelitian, agar penelitian memperoleh data lapangan/ empiris untuk memcahkan masalah penelitian dan menguji hipotesis yang telah ditetapkan (Sasmi, 2016). Data dengan mewawancarai langsung responden yang akan dijadikan sampel untuk memperoleh data yang dibutuhkan dengan bantuan daftar pertanyaan yang sebelumnya telah dipersiapkan oleh peneliti. Penentuan sampelnya dicari dengan memakai rumus slovin dalam Sasmi (2016), yaitu:

$$
\begin{aligned}
& n=\frac{26.125}{1+26.125(0,10)^{2}} \\
& n=\frac{26.125}{1+261,25} \\
& n=99,61
\end{aligned}
$$

Berdasarkan hasil perhitungan di atas, maka diperoleh jumlah sampel adalah 99,61 yang dibulatkan menjadi 100 orang.

\begin{tabular}{|c|c|c|c|c|c|}
\hline \multirow[t]{3}{*}{ Observec } & & & \multicolumn{3}{|l|}{ Predicted } \\
\hline & & & \multicolumn{2}{|l|}{ WTP } & \multirow{2}{*}{$\begin{array}{l}\text { Percentage } \\
\text { Correct }\end{array}$} \\
\hline & & & $\begin{array}{l}\text { Tidak Bersedia } \\
\text { Membayar } \\
\text { Willingness to } \\
\text { Pay Perbaikan } \\
\text { Lingkungan }\end{array}$ & $\begin{array}{l}\text { Bersedia } \\
\text { Membayar } \\
\text { Willingness to Pay } \\
\text { Perbaikan } \\
\text { Lingkungan }\end{array}$ & \\
\hline \multirow[t]{3}{*}{ Step 1} & \multirow[t]{2}{*}{ WTP } & $\begin{array}{l}\text { Tidak Bersedia } \\
\text { Membayar } \\
\text { Willingness to } \\
\text { Pay Perbaikan } \\
\text { Lingkungan }\end{array}$ & 8 & 6 & 57.1 \\
\hline & & $\begin{array}{l}\text { Bersedia } \\
\text { Membayar } \\
\text { Willingness to } \\
\text { Pay Perbaikan } \\
\text { Lingkungan }\end{array}$ & 3 & 83 & 96.5 \\
\hline & \multicolumn{2}{|c|}{ Overall Percentage } & & & 91 \\
\hline
\end{tabular}

\section{Hasil dan Pembahasan}

Tabel 2 Hasil Uji Ketepatan Klasifikasi

Sumber: data diolah. 
Sanjaya \& Saptutyningsih

Faktor-Faktor yang Mempengaruhi Willingness to Pay Pengunjung Wisata Teluk Kiluan ...

Berdasarkan tabel 2, hasil menunjukan bahwa pada 100 observasi, terdapat 91 observasi yang tepat pengklasifikasiannya oleh model logistic.

Tabel 3 Signifikansi dan Koefisien Regresi

\begin{tabular}{lllll}
\hline Variabel & B & Wald & Sig. & Exp(B) \\
\hline EDU & $\begin{array}{l}3.368^{* *} \\
\text { BR }\end{array}$ & 7.118 & 0.008 & 29.021 \\
& -1.262 & & & 1 \\
INC & $000^{* *}$ & 4.234 & 0.04 & 1 \\
FK & $.000^{* *}$ & & & \\
AK & 0 & 8.743 & 0.003 & 16.537 \\
& $2.806^{* *}$ & 12.477 & 0 & 0.741 \\
Constant & -0.794 & 0.046 & 0.831 & 0.419 \\
\hline
\end{tabular}

Keterangan: ${ }^{*}(\alpha=0,10) ; * *(\alpha=0,5) ; * * *(\alpha=0,01)$.

Sumber: Data diolah

\section{Pembahasan}

Hasil uji $\mathrm{t}$ dengan hipotesis variabel pendidikan literasi pelestarian Lingkungan menunjukkan bahwa variabel pendidikan literasi pelestarian lingkungan memiliki koefisien korelasi yang positif dan signifikan mempengaruhi willingness to pay untuk pelestarian lingkungan di objek wisata Teluk Kiluan. Hal ini dapat menjelaskan bahwa pengetahuan tentang literasi pelestarian yang lebih tinggi memiliki kesediaan membayar willingness to pay untuk pelestarian lingkungan di objek wisata Teluk Kiluan. Oleh karena itu, akibat dari literasi pelestarian lingkungan yang tinggi akan mempengaruhi lingkungan yang lestari sehingga tidak akan terjadi kerusakan lingkungan, pengunjung akan cenderung sadar dan menjaga keadaan lingkungan agar tetap lestari. Hal ini serupa dengan penelitian yang dilakukan oleh Sadikin, Mulatsih, Noorachmat, dan Arifin (2017) yang menyatakan bahwa variabel pengetahuan tentang pelestarian lingkungan berpengaruh positif dan signifikan terhadap willingness to pay.

Hasil uji t variabel biaya rekreasi menunjukkan bahwa variabel biaya rekreasi berpengaruh positif dan signifikan terhadap willingness to pay untuk pelestarian lingkungan di objek wisata Teluk Kiluan. Sehingga, dapat disimpulkan bahwa jika biaya rekreasi yang dikeluarkan lebih tinggi maka kesadaran pengunjung untuk membayar willingness to pay tinggi. Penelitian ini sejalan dengan penelilitan yang telah dilakukan oleh Akbar (2018) dan Ayu (2014) dengan variabel yang sama menyatakan bahwa variabel biaya rekreasi berpengaruh positif dan signifikan terhadap willingness to pay untuk pelestarian lingkungan objek wisata.

Dengan nilai koefisien korelasi positif dan signifikan, dapat dikatakan bahwa pendapatan mempengaruhi willingness to pay pengunjung untuk pelestarian lingkungan. Hal ini menandakan bahwa pendapatan yang lebih tinggi memiliki kesediaan membayar 
willingness to pay yang lebih besar pula untuk pelestarian lingkungan di objek wisata Teluk. Dengan begitu pendapatan objek wisata Teluk Kiluan akan meningkat dari pemasukan retribusi, sehingga pengelola objek wisata Teluk Kiluan akan mengalokasikan pendapatan yang lebih untuk perbaikan sarana dan prasarana untuk menunjang kenyamanan yang dibutuhkan oleh pengunjung, ketika pengunjung merasa nyaman melakukan rekreasi di objek wisata Teluk Kiluan maka pengunjung akan datang kembali dan akan menambah jumlah minat pengunjung yang akan datang. Hal serupa juga ditemui pada penelitian yang dilakukan oleh Hadisaputra (2011) yang menyatakan bahwa variable pendapatan berpengaruh positif dan signifikan terhadap willingness to pay untuk peningkatan kualitas objek wisata. Penelitian lain yang serupa juga dilakukan oleh (Sari, 2017) yang menyatakan bahwa bahwa variabel pendapatan berpengaruh positif dan signifikan terhadap willingness to pay untuk perbaikan kuallitas wisata di objek wisata Umbul Ponggok.

Variabel frekuensi kunjungan muncul dengan nilai positif dan signifikan terhadap willingness to pay, sesuai dengan hasil yang diharapkan. wisatawan yang sering berkunjung akan lebih mengetahui kelebihan dan kekurangan dari objek wisata tersebut, sehingga pengunjung akan semakin lebih peduli terhadap pelestarian lingkungan di objek wisata Teluk Kiluan. hasil penelitian ini juga sejalan dengan peneltian yang dilakukan oleh Akbar (2018); Hadisaputra (2018) Fauziyah (2017); Ayu (2014); Annisa dan Harini (2017).

Hasil Uji t dengan hipotesis dengan variabel alternative lokasi tidak memiliki pengaruh signifikan terhadap willingness to pay untuk pelestarian di objek wisata Teluk Kiluan. Hal ini tidak sejalan dengan penelitian yang dilakukan oleh Sadikin et al. (2017) yang menyatakan bahwa variabel alternatif lokasi berpengaruh secara signifikan terhadap kemauan pengunjung untuk membayar willingness to pay untuk menunjak nilai ekonomi wisata.

\section{Kesimpulan}

Berdasarkan pengujian dan hasil yang telah didapatkan, penulis bisa menyimpulkan beberapa hal di antaranya, nilai willingness to pay untuk pelestarian lingkungan di objek wisata Teluk Kiluan adalah sebesar 0,86. Dari jumlah 100 responden, Sebagian besar pengunjung bersedia membayar sebesar $\mathrm{Rp}$ 8.000. Variabel Pendidikan literasi pelestarian lingkungan, biaya rekreasi, pendapatan, serta frekuensi kunjungan berpengaruh signifikan terhadap willingness to pay untuk pelestarian lingkungan di objek wisata Teluk Kiluan. Sedangkan, variabel lokasi alternatif tidak berpengaruh signifikan terhadap willingness to pay untuk pelestarian lingkungan 


\section{Sanjaya \& Saptutyningsih}

Faktor-Faktor yang Mempengaruhi Willingness to Pay Pengunjung Wisata Teluk Kiluan ...

\section{Daftar Pustaka}

Akbar, M. Z. (2018). Willingness to Pay Pengembangan dan Perbaikan Kualitas Objek Wisata Tebing Breksi di Kabupaten Sleman. Skripsi. Ekonomi Pembangunan Universitas Muhammadiyah Yogyakarta.

Amalia, F. (2011). Analisis Kesediaan Membayar dalam Upaya Pelestarian Lingkungan Objek Wisata. Skripsi. Departemen Ekonomi Sumberdaya dan Lingkungan Fakultas Ekonomi dan Manajemeninstitut Pertanian Bogor.

Amanda, S. (2009). Analisis Willingness to Pay Pengunjung Obyek Wisata Danau Situgede dalam Upaya Pelestarian lingkungan. Skripsi. Departemen Ekonomi Sumberdaya dan Lingkungan Fakultas Ekonomi dan Manajemeninstitut Pertanian Bogor.

Annisa, T. M., \& Harini, R. (2017). Analisis Kesediaan Membayar WTP Untuk Mendukung ekowisata Berkelanjutan di Kawasan Wisata Gua Pindul, Kabupaten Gunung Kidul. Jurnal Bumi Indonesia, 6(4), 30-40. Diakses dari http://lib.geo.ugm.ac.id/ojs/index.php/jbi/article/view/914

Ayu, K. D. (2014). Faktor-faktor yang Mempengaruhi Willingness To Pay Keraton Yogyakarta untuk Pelestarian Objek Wisata Heritage. Yogyakarta. Ekonomi Pembangunan. Skripsi. Ekonomi Pembangunan Universitas Muhammadiyah Yogyakarta.

Fauzi, A. (2004). Ekonomi Sumberdaya Alam dan Lingkungan, Teori dan Aplikasi. Jakarta: PT Gramedia Pustaka Utama.

Fauziyah, S. S. (2017). Analisis Willingness to Pay untuk Perbaikan Kualitas Wisata Waduk Sermo di Kabupaten KulonProgo. Skripsi. Ekonomi Pembangunan Universitas Muhammadiyah Yogyakarta.

Hadisaputra, A. K. (2011). Pengelolaan Wilayah Pesisir Teluk Kiluan Kabupaten Tanggamus, Melalui Pengembangan Ekowisata. Tesis. Program Studi Magister Ilmu Lingkungan. Universitas Padjajaran.

Majid, R, H. (2008). Analisis Willingness to Pay Pengunjung terhadap Upaya Pelestarian Kawasan Situ Babakan, Srengsen Sawah. Jakarta Selatan. Skripsi. Institut Pertanian Bogor.

Sadikin, P. N., Mulatsih, S., Noorachmat, B. P., \& Arifin, H. S. (2017). Analysis Of Willingness to Pay on Ecotourism in Mount Rinjani National Park. Analisis Kebijakan Kebutanan. 14(1), 31-46. https://doi.org/10.20886/jakk.2017.14.1.31-46

Sasmi, N. A. (2016). Faktor-faktor yang Mempengaruhi Willingness To Pay Pengunjung Obyek Wisata pantai Goa Cemara Menggunakan Contingent Valuation Method (CVM). Skripsi. Ekonomi Pembangunan Universitas Muhammadiyah Yogyakarta.

Sekar, C. Surendran, A. (2010). Analisis EKonomi Kesediaan Membayar (WTP) untuk Melestarikan Keanekaragaman Hayati. Post Harvest Technology Center. India

Sugiyono. (2011). Metode Penelitian Kuantitatif Kualitatif D AN R\&D (cetakan ke-14). Bandung: Alfabeta. 